\title{
BEATAS Y POSESIÓN DEMONIACA: CONTRAMODELOS FEMENINOS E INQUISICIÓN ${ }^{1}$
}

\author{
BEATRIZ MONCó \\ Universidad Complutense de Madrid \\ bmonco@cps.ucm.es
}

\section{UNA ESPAÑA DORADA QUE PIERDE SU LUSTRE}

$\mathrm{D}$ esde una perspectiva cultural los siglos XVI y XVII constituyen una paradoja. Es un tiempo de claroscuros, de juego de contrarios, de mezcla sin fin, donde encontramos, a la vez, el triunfo de la razón y el espíritu, pero también las creencias más sorprendentes. Es la España del místico y del pícaro, de las grandes navegaciones, de los impresionantes misioneros, sin obviar el momento del miedo, la pérdida y la decadencia. Hablamos de una época que ha ido saliendo de profundas crisis económicas, políticas y sociales. Hambrunas, epidemias y guerras han ido socavando el ánimo y la sensibilidad de todo un pueblo y poniendo en duda y cuestión los fundamentos más sólidos de la sociedad europea. De hecho, el poder, tanto en su expresión política como social y espiritual, parece demostrar que la vida se vacía de contenido profundo y que no existe futuro más allá del momento. El miedo al porvenir, lo azaroso de la existencia, la fragilidad de lo humano, conducen hacia caminos complejos señalados mediante el carpe diem o, al contrario, las aventuras espirituales colectivas o íntimas. Como un grito desesperado escribe Pedro Galindo:

Nunca ha estado el mundo peor que en la era presente, nunca más malicioso, ni más deshonesto, ni más loco, ni más altivo, ni más desconcertado, ni más perdido, ni más desbaratado. Nunca los señores más absolutos, ni los caballeros más sin

\footnotetext{
1 Este artículo se ha desarrollado dentro del proyecto «La mujer frente a la Inquisición española y novohispana» (FEM2016-78192-P), I+D de Excelencia del Ministerio de Economía y Competitividad (MINECO), financiado por la Agencia Estatal de Investigación (AEI) y el Fondo Europeo de Desarrollo Regional (FEDER, UE).
}

Edad de Oro, XXXVIII (2019), pp. 75-87, ISSN: 0212-0429 - ISSNe: 2605-3314

DOI http://doi.org/10.15366/edadoro2019.38.004 
honra, los nobles más en bajeza, embarazados en viles mercaderías de la república; los ricos más crueles; los mercaderes más tramposos; los religiosos más indevotos; los que habían de ser más quietos más divertidos: las mujeres más libres; las doncellas más desvergonzadas; los hijos más inobedientes; los padres más descuidados; los amos más dejados; los criados más infieles; los hombres más impacientes y menos sufridos; pero tampoco nunca ha habido más engaño, ni reinado tanto la mentira (1678: 29).

Esta visión pesimista de un país decadente, que constituye la cara oscura de la España dorada, genera una doble vía a la hora de relacionarse con el mundo y la propia existencia. Por una parte, una extraordinaria creencia en todo lo posible; por otra, una reapropiación de la devotio moderna de siglos anteriores, más individual, más íntima, en la que tendría máxima importancia el lenguaje, el yo y su aniquilación, e incluso la exaltación del recogimiento.

Ambas vías van a traer consecuencias sociales y culturales de importancia porque, en cierto modo, abrirán caminos diferentes a los conocidos. Con la última estaríamos ante dos modos de entender la relación con la divinidad que se transformaría, en realidad, en dos maneras de comunicación con ella (una vocal y otra mental) y en una heterodoxia finalmente perseguida por la Inquisición (alumbrados, recogidos, molinistas, etc.), en tanto que representaba una ruptura con la autoridad y el magisterio eclesial. Simultáneamente, con la primera, estaríamos en la hora de los magos, hechiceros, buscadores de tesoros, brujas y endemoniadas; es decir, en el tiempo de todo lo creíble, en el momento en que el ámbito de lo real se hace tan grande que los límites se difuminan e incluso se borran.

\section{Mujeres y VALORES FEMENINOS}

En estos momentos y con tales circunstancias, el poder diseña un orden genérico que divide taxativamente a hombres y mujeres modelando actividades, espacios, roles y conductas. Además, los criterios para tal dicotomía se naturalizan y divinizan, es decir, se consideran propios de la naturaleza de cada cual porque, sencillamente, Dios lo ha querido así. Recuerda fray Luis de León:

¿Por qué les dio a las mujeres Dios las fuerzas flacas y los miembros muelles sino porque las crio, no para ser postas, sino para estar en su rincón asentadas?... Así, la buena mujer, cuanto para sus puertas adentro ha de ser presta y ligera, tanto para fuera dellas se ha de tener por coja y torpe (2005: 108).

De esta forma plantea una de las prescripciones más importantes para el conjunto femenino: su obligación de domesticidad. La división de espacios, rígida e inflexible como lo es el modelo cultural de género que la provoca, tiene una doble 
consecuencia para las mujeres: la prohibición de su movilidad y la custodia de su honra, es decir, la salvaguarda del honor. Un valor cultural central en esta sociedad, al que en este momento no podemos prestar la atención que merece, que ha constituido casi hasta nuestros días parte básica de la identidad femenina y de las culturas mediterráneas.

Este encerramiento femenino tiene matices importantes que habría que analizar aplicando ciertas variables interseccionales: la clase social, la edad, la etnia y, en el Barroco, la práctica religiosa. Pero, de una u otra forma, podemos afirmar que la honestidad de la mujer es doméstica, privada y de puertas adentro, pues estamos ante una sociedad que valora el encierro de las mujeres porque en su escala de valores significa decencia, feminidad, bondad, obediencia e incluso, como decíamos, cumplimiento de un orden divino. El espacio doméstico y los valores inherentes a él trazan y configuran el valor de la mujer, ya sea viuda, casada o soltera.

Paralelamente, estos valores se trasladan a los conventos convirtiéndolos en espacios similares, espacios de tránsito (entre lo profano y lo divino), espacios que rompen el encierro doméstico de las mujeres y las singularizan acercándolas al ideal. Es muy claro, además, que no se puede entender la clausura conventual sin tener en cuenta los valores de género que comentábamos: su encierro (domesticidad) y su inmovilidad. Además, es interesante señalar que precisamente la clausura fue un problema de primer orden tratado en Trento y continuamente reforzado por diferentes normativas eclesiásticas, incluso por encima de lo prescrito en cada orden concreta.

Podríamos, pues, señalar la continuidad que en el ordenamiento de género existe entre la casa y el convento. Ambos son espacios idóneos para la mujer y a veces simultanean sus funciones sin mayor problema. Así, por ejemplo, muchas veces los conventos son «casas de recogimiento» para esposas cuyos maridos deben realizar largos viajes e, incluso, para mujeres delincuentes que eran acogidas hasta su sentencia si se suponía que la cárcel pudiese horadar su virtud. Vemos que el valor honra, el sujeto mujer y el espacio no público forman un trinomio definidor de la condición femenina.

En el Barroco, por otra parte, proliferan los conventos y las religiosas. Unas veces porque se tiene verdadera vocación. Otras, por obligación e incluso violencia familiar a la hora de limpiar u ocultar manchas de honor que perjudican al linaje o por problemas económicos que impiden pagar dotes altas. En ocasiones, por continuidad de un proceso de socialización comenzado en la niñez; y, por último, hay que considerar también que muchas mujeres prefirieron el encierro conventual a contraer matrimonio y tener hijos.

Los destinos femeninos estaban muy marcados por las normas de género. Las mujeres pasaban de la autoridad del padre o el hermano mayor al dominio del esposo sin transición ninguna. Los trabajos solo se permitían a mujeres pobres y de 
baja condición; por tanto, era inconcebible cualquier intento de independencia o de existencia fuera de la casa del padre o el esposo. En realidad, la sociedad barroca construyó un fuerte vínculo entre la vida familiar y conventual cuando se trató de mujeres, lo que simbólicamente nos indica una extensión de la vida doméstica y familiar a un espacio que no lo es. Estamos ante un proceso de parentalización extendido. Una ficción de familia que llena los conventos de hermanas, padres y madres en un símil de unidad de parentesco donde encontramos señalados los valores que el poder exige a las mujeres e incluso las prebendas que cada hombre tiene sobre las que son suyas. Sabemos que, en general, las órdenes religiosas de varones guiaban a las de las mujeres, diseñaban su vida y sus vestidos e, incluso en algunos casos, indicaban personalmente qué hacer y cómo comportarse (como ejemplo nos sirve el padre Báñez e incluso fray García de Toledo y Teresa de Jesús).

Realmente, para comprender la idealización de la clausura no hay más que recordar que la profesión religiosa es un matrimonio simbólico con Cristo y que ambos quedan subsumidos en una relación esposo-esposa que lleva signos visibles e incluso así se representa culturalmente. Las monjas se convierten en un tipo de mujer ideal bajo la tutela de sacerdotes que guardan y cuidan de las mujeres propiedad de la divinidad. Así pues, solo dos opciones eran valoradas para las mujeres: el matrimonio o el convento. Ambas, además, representaban espacios domésticos y de encierro con una falta absoluta de independencia y movilidad para quienes se veían obligadas a tener comportamientos y vidas diseñados a través del sexo y el mandato de género consiguiente. No es extraño que muchas mujeres con deseos intelectuales vieran en la clausura un mejor modo de cumplirlos; es sabido que la escritora de la España moderna es una religiosa, a pesar de que encontremos alguna gloriosa excepción a esta regla.

Tampoco causa sorpresa el considerar que el ámbito de la religiosidad y, aún más, la expresión y desarrollo del espíritu, permitiera a las mujeres un cierto grado de libertad. Finalmente, la espiritualidad no necesita grandes espacios ni grandes públicos, y una pequeña celda silenciosa o, como veremos, un simple beaterio son espacios idóneos de reflexión y meditación inherentes a la hermenéutica anagógica, la ascesis y la comunicación con la divinidad.

Como decíamos al principio, los valores culturales de la época enlazan perfectamente con algunos movimientos espirituales que suponen un profundo corte doctrinal en su rechazo a todo lo que suponga una piedad externa, visible en signos, gestos y rituales. La experiencia de Dios se humaniza y la relación con Él se hace íntima y personal, no necesitando en su expresión ni siquiera la oración vocal. De este modo, la Iglesia y sus representantes pierden su papel intermediario que, además, ya no se necesita en este vis a vis con lo divino. Un acercamiento que traería consigo un fortalecimiento de la mística, quizás como nunca había habido, pero también comportamientos heterodoxos de quietistas, iluminados o 
molinistas. A ello debemos sumar un reforzamiento máximo del horizonte creencial y un protagonismo femenino en el ámbito del espíritu realmente innovador. Finalmente, las crisis agudas, como la que se vivía en esos momentos, «obligan a redefinir situaciones externas y a tomar nueva conciencia de sí mismo frente a ellas» (Lisón 1990: 38).

En este nuevo horizonte que abre la dedicación espiritual, las mujeres siguen condicionadas por sus experiencias de género. Tanto estas como los valores y exigencias inherentes a su ordenamiento se mueven con nosotras, atraviesan cualquier frontera a nuestro lado, sea física, ideológica, cultural o simbólica. El género acompaña nuestra vida y es, por tanto, desde la concreta posición genérica como interrogamos las normas, negociamos los cambios, elaboramos las estrategias y transgredimos los límites de las normativas. Ayer y hoy.

\section{Mujeres de Conflicto: el caso de las beatas}

Durante la Edad Media parte de Europa, especialmente los Países Bajos y Alemania, ve surgir y extenderse grupos de mujeres con renovada espiritualidad que se conocen con el nombre de beguinas. De hecho, algunos beguinatos famosos, como el de Brujas, han llegado hasta nuestros días y nombres como el de Beatriz de Nazaret, Matilde de Magdeburgo, Margarita Porete o Hadewichj de Amberes forman un conjunto que ha pasado a la historia. En España y en la época que nos ocupa, las llamadas beatas comparten algunas de las características de las beguinas, pero el movimiento beateril adquiere unas singularidades que lo conforma como peculiar. Empecemos por el nombre.

Beata es un término de amplio significado que genera algunas diferencias según el contexto geográfico y cultural en el que nos movamos. En el País Vasco y Navarra encontramos términos sinónimos a beata como «serora» y «freyla» (o «fraylas»), «benitas» e incluso «benoîtes» y, en ocasiones, aunque más raramente, se habla de ellas como de «ermitañas» (Arana 1992: 89). Los tres primeros nombres, además, aparecen indistintamente en documentos eclesiásticos. Con ellos se designan a las mujeres que ayudan en las tareas de la parroquias o de las ermitas, ocupándose también de los pobres, enfermos y necesitados y, en algunos casos, hasta de la instrucción de los niños. En el resto del territorio español suele utilizarse la palabra «beata» de un modo general, pudiendo constatar que hace referencia a «mujer que viste hábito religioso y vive con recogimiento sin pertenecer a ninguna comunidad»; también «la que vive con otras en clausura o sin ella bajo cierta regla» e incluso «mujer dada a devociones» (Casares 1997). En conjunto, podríamos decir que son mujeres que suelen vivir en comunidad, pero que no hacen votos solemnes (lo que sería una diferencia radical con las monjas), se dedican a 
la oración y a las obras de caridad, trabajan manualmente en caso de necesidad y suelen mantenerse célibes, a pesar de que algunas de ellas han estado casadas o incluso el esposo vivo les permite tal retiro. Habitualmente, también, hacen promesa (algunas voto) de castidad.

En realidad estamos ante un tipo cultural complejo. La beata es diversa, difícil de catalogar por sus características y escurridiza cuando la queremos clasificar por sus hechos y representaciones culturales. Aun así, podríamos intentar un diseño amplio, que nos diera una idea general, sabiendo, eso sí, que siempre hay alguna que se encuentra en el intersticio del modelo o que siempre hay quien no cumple con los requisitos. Por otra parte, el tiempo es una variable importante que refuerza o desfigura el modelo beateril. A pesar de que generalmente las homologamos, no es lo mismo hablar de beguinas que de beatas y, desde luego, no es igual analizar estas últimas en la Edad Media o en la Moderna. De hecho, la España barroca y la religiosidad femenina fueron claves para la reconstrucción singular de un tipo de beata del que posteriormente hablaremos. Distintos movimientos religiosos y el proceso de Contrarreforma tuvieron mucho que aportar en las expresiones íntimas de espiritualidad y en la configuración cultural de la doctrina $\mathrm{y}$, por tanto, sesgaron el pensamiento y la conducta de muchas de estas mujeres.

Tentativamente, entonces, podemos hablar de tres clases de beatas: primero, la beata que, aun con sus singularidades, refleja mejor las características del tipo. Una mujer de acendrada espiritualidad, que se aleja de la vida externa y se encierra, sola o en compañía de otras, en casas de oración. Son mujeres que, por diversas razones, no desean reglamentar su vocación, aunque algunas hacen voto de pobreza y castidad, y no ingresan en un convento, aunque muchas de ellas pertenecen a órdenes terceras y llevan el hábito correspondiente. Viven en ocasiones de sus propias rentas o de dádivas de quienes confian en ellas y las protegen. Algunas son llamadas maestras de espíritu pero, en ocasiones, admiten sin problemas dirección espiritual de sus confesores y guías religiosos. Como ejemplo, y a pesar de que presentan ciertas disonancias con una imagen perfecta, podríamos situar en este caso a Francisca López o a la muy conocida Isabel de la Cruz.

Esta imagen-tipo se desdibuja, sin embargo, al acercarnos a otras beatas que representan «la beatitud como tapadera de la típicamente urbana hechicería amatoria» y que en realidad busca «estimación y acomodo» (Sánchez Lora 1988: 354). Un tipo, además, bien tratado en la literatura del momento que presenta imágenes solapadas con las alcahuetas y las brujas, pero que en la realidad acaban, en ocasiones, en manos de la Inquisición o abandonadas por sus seguidores desengañados. En nuestra opinión, estos casos son mera superposición de muestras externas de devoción, más o menos similares a las de las beatas, que no son sino instrumento al uso para conseguir otro tipo de beneficios. No olvidemos que es la época de la picaresca, una forma de vida que traspasa ámbitos y conductas y 
que, de nuevo, no hablamos de tipos culturales limpios y con límites claros sino de yuxtaposiciones y liminalidades, de tipos calidoscópicos, en los que las piezas son las mismas, pero que en su combinación concreta ofrecen imágenes y representaciones diferentes.

Entre estos dos tipos, en realidad extremos de un continuum, encontramos una diversidad de mujeres que, en mayor o menor medida, cumplen con el tipo-beata, pero al tiempo significan su rol mediante características personales acordes a la espiritualidad del momento y su creatividad y donde la figura de Satanás (y finalmente el Santo Oficio) entra de lleno de distintas maneras.

\section{Beatas y demonios o La BÚsqueda de sí Mismas}

Desde la famosa «Querelle des Femmes» podemos rastrear un movimiento no organizado proclive a la defensa de la educación femenina. Educación entendida, a veces, en sus mínimos de lectura y escritura, pero que permite que las mujeres puedan gestionar su aprendizaje y acercamiento a las experiencias espirituales de teólogos, ascetas y místicos, y entender así sus propias vivencias en un marco dominado tradicionalmente por los varones y la doctrina eclesiástica. Los beaterios e incluso en ocasiones las casas particulares de las beatas, se convierten en lugares de reunión donde se discuten e interpretan las Sagradas Escrituras fuera del canon normativo. De hecho, muchas beatas comienzan a mostrar una religiosidad diferente, no acorde con el común de la época. Las lecturas de san Pablo, la exégesis bíblica, la comunión habitual, las discusiones colectivas sobre temas religiosos... son conductas que causan extrañeza, sobre todo porque provienen de mujeres peculiares que viven solas, sin varones y sin estar sujetas a orden religiosa alguna.

Poco a poco, España entera es territorio de beatas. Madrid, Toledo, Baeza, Cuenca, Guadalajara, Plasencia, Sevilla, Cádiz, Alicante, Ávila, Trujillo, Llerena, Camarena, Uclés, Alcalá de Henares y decenas de lugares más, son asentamiento de beaterios. Su progresión alarma a las autoridades competentes e incluso el Consejo de la Suprema redacta un documento con el que se intenta paliar los problemas que están surgiendo (Huerga 1978). Problemas, curiosamente, que nos dan muestra de lo heterogéneo del movimiento beateril. No son solo, como se ha apuntado, «mujeres de extracción baja» (Lisón 1990: 42), sino que muchas de ellas tienen bienes para formar y sostener el beaterio e incluso para echar un pulso al orden eclesiástico que pretende someterlas a una regla religiosa o, al menos, cuenta con mentores y seguidores que le permiten su retiro. Por otra parte, es bueno no olvidarlo aunque no lo podamos tratar en este momento, las mismas órdenes pujan también por obtener sus favores, su elección y su nombre, al igual que ocurre con algunas religiosas de fama. Las beatas se multiplican y con ellas la 
heterogeneidad de sus posiciones sociales, sus seguidores y sus ejemplos de vida y opinión. Las beatas, que como mujeres debían enmudecer en público, comienzan a asentar palabra y enseñanza.

En consonancia con la doctrina y el poder sociopolítico y eclesiástico, son precisamente estos aspectos los que preocupan a las autoridades. Son conocidas, son seguidas, son aplaudidas y son comentadas. Su fama, palabras y obras corren por las calles. Su espiritualidad es además conocida porque sus seguidores, algunos clérigos y confesores, se encargan de contar cada una de las manifestaciones que exteriorizan y que, en general, se centran precisamente en su cuerpo, de tal forma que la dejadez de sus miembros, su quietismo, su oración mental, vocea silenciosamente su singularidad: los éxtasis, los arrobos, las pérdidas de pulso y sentido son señales de su perfección espiritual. Aún más, cuando en sus visiones y en su cuerpo se palpa la presencia del diablo. Veamos el ejemplo de Margarita Agulló relatado por fray Jaime Sanchís:

Viendo un religioso [...] a la Sierva de Dios arrobada y tendida en el suelo en cruz en una capilla, y que passavan ya de las doze horas de mediodía, avisó a su Confessor de cómo quería cerrar las puertas [...] y se lo impedía estar la devota Virgen arrebatada en la Iglesia. Fueron los dos donde estava, y halláronla en un arrobo profundíssimo en una capilla, tendida en el suelo de largo a largo, estendidos los braços en forma de cruz, y el un pie sobre el otro. Admiráronse de verla en semejante figura ${ }^{2}$, y llegando su Confessor y asiéndole la cabeça y forcejeando quanto pudo para levantarla, no solo no pudo mover ni menear la cabeça mas que si fuera un gran peñasco, pero quedó cansadissimo y como descoyuntado de la mucha fuerça que hizo y con muy grande admiración [...] aunque con harta dificultad la levantaron del suelo: y mandándola yrse a su casa, dio un salto tan grande que salvó las cinco gradas del altar mayor, y en poniendo los pies en el suelo, se quedó arrobada, estendidos los braços (1607: 232 y ss.).

El caso de esta beata no es único. Llagas, raptos, arrobos continuados, dolores inespecíficos y visiones son comunes a muchas beatas. Los tenemos presentes en Mariana de Jesús, Catalina de Jesús, Ana de los Santos, Beatriz de Robles, Antonia de San Francisco, Juana de Jesús, María Romera, María González, o Francisca González. Y también es similar su trato con Satanás, igual que había ocurrido con las místicas ${ }^{3}$. Unas veces, como indica el mismo Sanchís, porque el demonio «no

2 Sanchís está describiendo la postura de la crucifixión de Cristo, porque la beata tiene «el sentimiento de las llagas» como prueba de su espiritualidad. Su confesor le toca una mano y el costado, y Margarita hace ver «afligida de un dolor agudo» y con un «grande suspiro», el inmenso dolor que le produce.

3 Conviene recordar el proceso de Teresa de Jesús al respecto y pensar cómo en la época ella es una de las mujeres más imitada tanto en los conventos como en los beaterios. 
puede sufrir» lo que la vida espiritual de estas mujeres representa para la grandeza de Dios, de ahí que las confunda mediante embelesos y engaños, y lógicamente sea el enemigo a batir. Otras, la relación va más allá y varias beatas resultan poseídas por los demonios. Todo ello, además, en un momento cultural donde el Maligno es habitual y cotidiano, con presencia en los púlpitos, la doctrina, la teología y la demonología erudita, el teatro, los caminos, las aguas y el aire. La cultura barroca no se entendería sin contar con que Satán, signo hueco, se significa y potentiza en sus representaciones culturales y el imaginario colectivo.

En la lucha desigual que mantienen el demonio, combate contra su cuerpo para aniquilar su alma. Unas veces las golpea transformado en animal; otras las tienta en su sexualidad para quebrantar sus promesas; a veces las maltrata abrasando sus gargantas de sed incontenible, deteniendo sus pulsos, golpeándolas contra el suelo y las paredes, moliéndolas a palos, coceándolas o quebrantándoles los huesos. Toda violencia es buena para que las beatas dejen sus oraciones y destruyan su vida espiritual; lo llamativo es que en esta contienda cuerpo a cuerpo el de estas mujeres reacciona exactamente igual que lo hacen las poseídas por Satán, con lo que no es raro encontrar que a algunas beatas les hacen exorcismos a fin de comprobar si están o no arreptas.

Frente a las beatas que combaten al diablo exteriormente, hallamos aquellas que sí admiten estar poseídas por el Maligno y muestran todas las señales que la doctrina estipula al respecto e incluso más, pues algunas, María Martínez es un ejemplo, llegan a sostener que todos tenemos «demonios de la guarda» (Sarrión Mora 2003: 195). Lo que hace a los diablos compañeros de vida de los seres humanos, muy especialmente de las mujeres. Satanás, por tanto, se hace presente en la vida de las beatas y lógicamente en la observancia de los inquisidores. Ya no es solo que sean mujeres extrañas en su comportamiento, movilidad y vestimenta. Tampoco parece suficiente que tengan arrobos, éxtasis y visión y que incluso alguna sea acusada de hechicería. Es que también están creando modelo y reforzando un tipo sospechoso sobre el que el Santo Oficio tiene puesta su vigilancia desde hace tiempo $\mathrm{y}^{4}$ del que huyen algunos confesores a fin de evitarse problemas.

El catálogo de las declaraciones de beatas encuentra sus límites en la construcción teológica y doctrinal del demonio y sus posibilidades. Los diferentes juicios inquisitoriales repiten una y otra vez las características que la doctrina especifica para los posesos. Todas ellas hablan de revelaciones (de Dios, la Virgen, los santos e, incluso, las ánimas del Purgatorio), todas relatan los dolores de Cristo en sus cuerpos, todas viven experiencias maravillosas que son signo de singularidad y todas ellas encuentran quienes les escuchan y animan, especialmente sus confesores.

$4 \quad$ Pensemos que Teresa de Jesús, Ignacio de Loyola, Juan de Ávila o Juan de la Cruz estuvieron en la mira inquisitorial como generadores de nuevas espiritualidades. 
Algo que preocupa a quienes dedican sus esfuerzos a indicarles el camino ideal y escriben verdaderos compendios de normas para ellas (Pérez de Valdivia 1585).

Efectivamente, en algunas ocasiones, las beatas fueron arropadas y empujadas en sus conductas por sus guías espirituales y confesores, lo que constituyó un aspecto más de sanción a la hora de los juicios inquisitoriales ${ }^{5}$. En consonancia con el ethos de la época, su santidad se refleja en las manifestaciones que los diablos hacen ante el público ${ }^{6}$ que las sigue y protege; el caso de las beatas andaluzas y extremeñas es, según Huerga (1978), totalmente paradigmático en este aspecto. Como lo es que Francisca de los Apóstoles quisiera fundar un beaterio especial para las exposesas toledanas.

En este nuevo panorama espiritual el cuerpo de las posesas no solo se retuerce y su boca aúlla, maldice o impreca, sino que tales desmanes se interpretan desde la clave de la elección divina, de la maravilla y el misterio. Son las elegidas de Dios. Son sus mensajeras. Son el hogar del Espíritu Santo. Son, lo vemos, pura contradicción cultural y espiritual. Y con este nuevo estado, abrazando un mal que representa un bien, se enfrentan a su condición de mujeres, al mundo, al poder y a la Inquisición.

\section{Algunas conclusiones}

Los modelos de género son construidos desde el poder (político, económico, social, religioso, simbólico) y bajo el supuesto de que son modelos únicos, cerrados y de obligado cumplimiento. Sin embargo, una mínima hermenéutica de la sospecha nos permite comprobar que si las normas se repiten una vez y otra es porque no se cumplen en su totalidad, lo que nos hace inferir que a la norma de género inflexible siempre se le descubren huecos que permiten a las mujeres atenuar sus mandatos y, a veces incluso, hasta sus castigos. Ahora bien, desde el no cumplimiento del rol impuesto o la norma prescrita a la huida creativa hay un trecho grande. Un camino difícil, con varios ramales, que debe permitir que la subjetividad de cada protagonista encuentre acomodo e instrumentos para su respuesta al patriarcado.

El ejemplo de las beatas nos ha permitido comprobar que la nueva espiritualidad, propia de la época histórica que tratamos, se transforma en un cauce perfecto

5 A veces las autoridades religiosas se conforman con separar al fraile comprometido en el tema. Un buen ejemplo es el caso de fray Francisco García Calderón, relacionado con una beata sevillana y traído a Madrid para ser prior del convento de San Plácido. Años después las monjas benitas protagonizarían uno de los casos más famosos de la corte (Moncó, 1989).

6 Los conjuros que realizaba Gaspar Lucas se hacen famosos por su espectacularidad y el número de presentes. 
para recorrer otros caminos personales y colectivos. En estas mujeres, además, podemos apreciar una tensión con el ordenamiento de género muy notable. Pensemos, como antes decíamos, que si el ideal femenino es la mujer doméstica y sin movilidad, representado fielmente por la mujer hogareña e idealmente por la monja, estas mujeres que ni se casan, ni tienen hijos, ni obedecen a marido alguno, ni se encierran tras los muros de un convento ni hacen voto de obediencia y, además, en caso de necesidad, salen al exterior a trabajar, pedir limosna o demandar donaciones son mujeres antifemeninas y al límite. La clausura, por tanto, no es su ámbito sino el mundo y la calle. El silencio no es su morada y la palabra su espada contra el mundo. Estamos evidentemente ante mujeres contramodelo, mujeres extrañas que no cumplen las normas de género impuestas y, por tanto, mujeres sospechosas socioculturalmente e incómodas para el poder. Por si estas características fueran pocas, parecen despreciar aquellos requisitos que conforman la imagen de la feminidad. Son mujeres que no atraen sexualmente por su aspecto ni emplean los artificios comunes para ello: no utilizan chapines, algunas se rapan el pelo y, como decíamos, se ciñen el hábito de terceras que desde luego no tiene función de embellecer. Seducen, en realidad, su espíritu y su palabra, su negativa, incluso, a continuar con lo estipulado. El control social que conlleva la separación de sexos se quiebra con ellas, situándolas en otro ámbito diferente que dificulta su dominación genérica aunque personalmente se sujeten a otros vínculos y otras obediencias.

Decíamos anteriormente que algunas de estas mujeres son maestras de espíritu, lo que sin duda alguna representa un empoderamiento espiritual (y en cierta medida también social) con respecto al conjunto habitual de mujeres. Es importante saber que su maestría no solo se dirige a quienes viven con ellas, sino que en ocasiones son hombres quienes forman su grupo de adeptos con lo que ponen del revés una jerarquía que, en la época, se pensaba proveniente del mandato divino y por tanto inmutable.

Las beatas generan procesos de resistencia, de negociación, de negación, de vías paralelas y de usos diferentes de lo permitido. Elaboran estrategias múltiples, dispersas, singulares que les permitieron no solo dislocar algunas preceptivas del orden de género sino crear otros caminos, no siempre ortodoxos, para dar rienda a sus deseos, sus agencias, sus vidas y su libertad. Independientemente de las variaciones singulares que leemos en los procesos inquisitoriales, incluso sin contar con sus objetivos concretos y con sus errores espirituales y personales, estamos ante mujeres que, parafraseando a Benedetti, se deciden a ser alguien en vez de algo. Otra cosa, muy diferente, es el coste que pagaron por ello. 


\section{BIBLIOGRAFÍA}

Arana, María José (1992). La clausura de las mujeres. Madrid/Bilbao: Ediciones Mensajero/Universidad de Deusto.

CASARES, Julio (1997). Diccionario ideológico de la lengua española: desde la idea a la palabra, desde la palabra a la idea. Barcelona: Gustavo Gili.

Galindo, Pedro (1678). Verdades morales en que se reprenden y condenan los trajes varios, superfluos y profanos, con otros vicios y abusos que hoy se usan, mayormente los escotados deshonestos en las mujeres. Madrid: Impreso por Francisco Sáenz.

HuErga, Álvaro (1978). Historia de los alumbrados. Madrid: Fundación Universitaria Española.

LEÓn, fray Luis de (2005). La perfecta casada. Palencia: Simancas Ediciones.

Lisón Tolosana, Carmelo (1990). Demonios y exorcismos en los siglos de oro. Madrid: Akal.

Moncó, Beatriz (1989). Mujer y demonio, una pareja barroca. Madrid: Instituto de Sociología Aplicada.

Pérez de Valdivia, Diego (1585). Aviso de gente recogida y especialmente dedicada al servicio de Dios. Barcelona: Hyerónimo Genoués.

SÁnchez Lora, José L. (1988). Mujeres, conventos y forma de la religiosidad barroca. Madrid: Fundación Universitaria Española.

SAnchís, fray Jaime (1607). Relación breve de la vida, virtudes y milagros de la humilde Sierva del Señor Sor Margarita Agullona, beata profesa de la orden del Seráfico padre S. Francisco. Valencia: Casa de Iuan Chrysostomo Garriz.

SARrión Mora, Adelina (2003). Beatas y endemoniadas. Mujeres heterodoxas ante la Inquisición. Siglos XVI a XIX. Madrid: Alianza Editorial.

Recibido: 30/07/2019

Aceptado: 22/08/2019 


\section{wa}

BEATAS Y POSESIÓN DEMONIACA: CONTRAMODELOS FEMENINOS E INQUISICIÓN

RESUMEN: En los siglos XVI y XVII se extienden por España grupos de mujeres que resultan insólitas a ojos de la sociedad, de la doctrina y de la Inquisición. Las beatas viven solas, sin obediencia a padres y maridos, y de forma independiente. No son monjas aunque algunas llevan hábito, y prometen castidad aunque no realizan votos. Son muestra clara de una nueva espiritualidad que las hace sospechosas, como mujeres y como católicas. Muchas de ellas encuentran en la posesión demoniaca un camino de perfección.

PALABRAS ClaVE: beata, espiritualidad, género, poder.

\section{Blessed Women and Demonic Possession: Female Counter-Models and Inquisition}

Aвstract: Groups of women, unwonted in the eyes of society, doctrine, and Inquisition, spread throughout Spain in the $16^{\text {th }}$ and $17^{\text {th }}$ centuries. The Blessed live on their own, with no abidance to a father or husband. Although they wear the habit, they are not nuns; and although they promise chastity, they take no vows. As both women and Catholics, they raise suspicion as a clear sign of a new spirituality. Many find, in the demonic possession, a path to perfection.

KEYwORDS: blessed, spirituality, gender, power. 